\title{
(t)
}

\section{ECONOMIA VERDE: A NOVA OFENSIVA IDEOLÓGICA DO ECOCAPITALISMO}

Green Economy: capitalism's new ideological offensive

\author{
Nailsa Maria Souza Araújo ${ }^{1}$ \\ Maria das Graças e Silva²
}

\section{RESUMO}

O presente artigo traz problematizações acerca do conceito de "economia verde", conforme vem sendo divulgado e incentivado pelo Programa das Nações Unidas para o Meio Ambiente (PNUMA). Propõe-se a analisar os fundamentos deste conceito e desta estratégia de reorientação do desenvolvimento capitalista em pleno período de exponenciação de sua longa crise estrutural. Metodologicamente, explora e analisa documentos e textos relacionados à temática. Destaca a anarquia da produção capitalista para desvelar sua incompatibilidade com uma dinâmica sustentável. Conclui que é a economia verde uma ofensiva ideológica do capital, na sua busca de encontrar mecanismos de exacerbação das potencialidades lucrativas de exploração do meio ambiente, mercantilizando, ao extremo, os recursos naturais. PALAVRAS-CHAVE

Economia Verde. PNUMA. Ofensiva ideológica. Anarquia da produção.

\section{ABSTRACT}

This paper discusses the concept of "green economy" as it has been publicized and encouraged by the United Nations Environ-

${ }^{1}{ }^{\text {Prof }}$.Dr ${ }^{\text {a }}$ do Departamento de Serviço Social/Programa dePós-Graduaçãoem Serviço Social, Universidade Federal do Sergipe(UFS). E-mail: <nayarauj05@yahoo.com.br>. ${ }^{2}$ Prof ${ }^{a}$. Dr ${ }^{a}$ do Departamento de Serviço Social da UFPE. E-mail: <graca_pe@ yahoo.com.br>. 
ment Programme (UNEP). It aims at analyzing the fundamentals of this concept and of the reorientation strategy of capitalist development in the middle of a period when its long structural crisis has increased exponentially. The study methodologically explores and analyzes documents and texts related to the theme. It highlights the anarchy of capitalist production to unveil its incompatibility with a sustainable dynamics. It concludes that green economy is an ideological offensive of capital, as it seeks new ways to exacerbate the potential profits from environmental exploitation, commodifying natural resources.

\section{KEYWORDS}

Green Economy. UNEP. Ideological offensive. Anarchy of production.

Submetido: 15/6/2012

Aceito: $12 / 7 / 2012$

\section{INTRODUÇÃO}

A agenda ambiental brasileira e mundial tem se deparado com um novo conceito, amplamente divulgado, embora não tão discutido: a Economia Verde. Tendo os seus fundamentos no chamado ambientalismo empresarial - que ganha força nos anos 90 - foi, posteriormente, ampliado pelo Programa das Nações Unidas para o Meio Ambiente (PNUMA), o qual tratou de oferecer um conjunto de problematizações e indicações em torno deste conceito com o objetivo de orientar governos e entidades civis e empresariais (PNUMA, 2011).

O cerne do citado documento aponta para uma necessária mudança dos rumos no debate sobre o "estilo" de desenvolvimento "marrom", para referir-se a posturas de empresas, governos e sociedades que exibiram seculares descasos com o meio ambiente. Trata-se, agora, de realizar uma transição para um novo modelo, efetivamente sustentável. Se os gargalos para a efetivação dos princípios da sustentabilidade devem-se, ainda segundo o documento, ao fato de que a maioria das estratégias de crescimento e desenvolvimento econômico incentivou o acúmulo de capital físico e financeiro, desconsiderando os fatores ambientais, "hoje em dia existe um crescente reconhecimento de que a realização da sustentabilidade se baseia quase que inteiramente na obtenção do modelo certo de economia" (PNUMA, 2011, p. 9). Em outras palavras, "esverdear" a economia é 
tomado como caminho certo e seguro para a obtenção de uma sociedade sustentável.

É inegável que a ideia sugerida pelos pensadores da Economia Verde exerce um apelo ideológico, posto que "verde" tem uma conotação que aponta para a representação de todos os que se preocupam com o meio ambiente, com a saúde dos ecossistemas e com o planeta. Contudo, ao analisar os argumentos e estratégias indicadas, é preciso se perguntar: estaríamos em face de uma reviravolta na condução dos rumos da produção de riquezas e, portanto, das relações sociedade-natureza?

A realização da Conferência das Nações Unidas para o Meio ambiente - Rio $+20^{3}$ - levou os meios de comunicação a propalarem a temática e a estratégia da economia verde, considerando, sobretudo, tratar-se do tema norteador do referido evento - bem como deverá orientar o debate no próximo período - razão pela qual se faz imprescindível a análise crítica de tal propositura. O objetivo deste artigo é problematizar os fundamentos da Economia Verde, demarcando a sua natureza de classe e seu caráter de ideologia, posto que se destina, conforme iremos apontar aqui, a oferecer amparo e justificação pseudoética às novas investidas capitalistas sobre os recursos planetários.

A tese que delineamos neste artigo trata de afirmar que o conceito em questão, longe de indicar uma transição a um modelo sustentável de desenvolvimento para o capital, haja vista sua impropriedade, representa mais uma ofensiva ideológica e política das grandes corporações e de seus "intelectuais orgânicos”, no sentido de alargar as fronteiras da acumulação capitalista por meio da conversão do conjunto dos ecossistemas e de serviços ambientais em novos nichos de mercado. Em síntese, estamos em face do aprofunda-

\footnotetext{
${ }^{3}$ A Conferência tem dois temas centrais: A Economia Verde no contexto do desenvolvimento sustentável e da erradicação da pobreza; e a estrutura institucional para o desenvolvimento sustentável. Segundo o site oficial da Conferência (http://www.rio20.gov.br/sobre_a_rio_mais_20): “A Rio+20 é assim conhecida porque marca os vinte anos de realização da Conferência das Nações Unidas sobre Meio Ambiente e Desenvolvimento (Rio-92) e deverá contribuir para definir a agenda do desenvolvimento sustentável para as próximas décadas. O objetivo da Conferência é a renovação do compromisso político com o desenvolvimento sustentável, por meio da avaliação do progresso e das lacunas na implementação das decisões adotadas pelas principais cúpulas sobre o assunto e do tratamento de temas novos e emergentes".
} 
mento dos processos de mercantilização da natureza para atender a voracidade do capital em sua profunda crise estrutural.

\section{ECONOMIA VERDE: AFINAL, A QUE SE PROPÕE?}

Para leitores mais desatentos, o relatório do PNUMA pode seduzir, em princípio, pelo que anuncia como objetivos da economia verde - a reafirmação dos princípios da sustentabilidade - para, em seguida, oferecer um conjunto de indicações seguras de sua efetiva implementação. Trata-se de

Uma economia que resulta em melhoria do bem-estar da humanidade e igualdade social, ao mesmo tempo em que reduz significativamente riscos ambientais e escassez ecológica [...]. A sustentabilidade continua sendo um objetivo vital a longo prazo, mas é preciso tornar a economia mais verde para chegarmos lá (PNUMA, 2011, p. 9).

A base do argumento sugerido no referido texto é que a expansão dos negócios requer a adoção de um novo paradigma produtivo, caucionado na incorporação de fatores ambientais nos negócios, a fim de assegurar as condições de expansão da produção futura, eliminando os obstáculos relativos à escassez de recursos e os riscos de colapsos em certas atividades econômicas, a exemplo da indústria pesqueira. Diz o texto:

Este recente impulso para um conceito de economia verde, sem dúvida, foi ajudado pela grande desilusão em relação ao nosso paradigma econômico predominante; uma sensação de fadiga emanando das várias crises simultâneas e falhas de mercado vividas durante a primeira década do novo milênio, incluindo, principalmente, a crise financeira e econômica de 2008 (PNUMA, 2011, p. 8).

Nestes termos, os supostos da ecoeficiência ${ }^{4}$ tornam-se evidentes, com seu apelo técnico-científico passando a comandar esse

\footnotetext{
${ }^{4} \mathrm{~A}$ "ecoeficiência" é uma corrente que surgiu da incorporação, pelo Capitalismo, de um discurso ambientalista que emergia das lutas sociais do final da década de 1960. Defende o emprego da racionalidade técnica na mitigação dos impactos ambientais e riscos à saúde humana advindos das atividades industriais, da agricultura e da urbanização. A principal preocupação dos adeptos dessa corrente está na desvinculação entre crescimento econômico e degradação ambiental. Propõe economizar matéria e energia mediante uma revolução da eficiência (ANTUNES, 2011).
} 
tipo de estratégia ambientalista. Trata-se de apontar os limites do modelo anterior, com o objetivo de tornar mais adequadas as condições para a expansão capitalista por meio da adoção de uma racionalidade técnica voltada à mitigação dos impactos ambientais e riscos à saúde humana oriundos da produção industrial, da agricultura e da urbanização, além de economizar matéria e energia com uma revolução da eficiência (ANTUNES, 2011).

É possível identificar, de pronto, uma recusa explícita dos ideólogos da ecoeficiência quanto à realização de uma crítica radical às origens da destrutividade ambiental, fundada na apropriação privada dos recursos naturais planetários e em sua conversão em fatores de produção; antes, passam a afirmar a necessidade de submeter o "ambiente comum" (mares, rios e atmosfera) aos desígnios do mercado. Tudo passa como se a racionalidade mercantil pudesse ser controlada por si mesma, desde que dotada de uma suposta ética social e ambientalmente sustentável.

O conceito de economia verde também não é expresso com grande clareza no Rascunho Zero da Conferência Rio+20, embora seja seu tema central. Segundo Löwy (2012, não paginado).

Não é por acaso que os redatores do tal "rascu-
nho" preferem deixar o termo sem definição, bas-
tante vago. A verdade é que não existe economia
em geral: ou se trata de uma economia capitalista,
ou de uma economia não-capitalista. No caso, a
"economia verde" do rascunho não é outra coisa
do que uma economia capitalista de mercado que
busca traduzir em termos de lucro e rentabilidade
algumas propostas técnicas "verdes" bastante li-
mitadas (LÖWY , 2012).

A economia verde propõe, para além da mitigação dos impactos da atividade econômica, um conjunto de mecanismos destinados a favorecer a expansão das fronteiras do processo de acumulação por meio da intensificação da lógica mercantil como mediação fundamental das relações entre sociedade e natureza. Estes mecanismos são de três ordens:

\section{a) Incorporação dos serviços ambientais aos circuitos mercantis, especialmente ao mercado financeiro.}


Trata-se da instituição de mecanismos de Pagamentos por Serviços Ambientais (PSA), o que implica a conversão dos processos e produtos disponíveis na natureza em mercadoria. A utilização do conceito de "capital natural" é bastante elucidativa das intenções do capital em face do meio ambiente. Diz o texto: "Valores econômicos podem ser estimados para esses serviços ecossistêmicos [...]. Bens naturais, tais como florestas, lagos, pântanos e bacias fluviais são componentes essenciais do capital natural a nível de ecossistema" (PNUMA, 2011, p. 13).

Aqui, tem-se como um dos exemplos mais avançados desta tendência as transações envolvendo os créditos de carbono. Para além da constatação de que este instrumento não vem se revelando eficaz no combate às mudanças climáticas, corre-se o risco de que este venha a reduzir-se a uma operação financeira para dar lucros aos seus investidores, permitindo que um dado ecossistema seja prejudicado para favorecer a exploração comercial do outro, como afirmação do direito de poluir. Estão em xeque, neste caso, os princípios da Economia Ecológica e seus esforços por incorporar ao cálculo financeiro os "serviços" e recursos ambientais, na expectativa, notadamente falaciosa, de compatibilizar acumulação capitalista e preservação ambiental.

Para Ribeiro (2011, p. 10), estes mecanismos

[...] são muito atrativos para as empresas contaminadoras e para os investidores de risco porque, por um lado, abrem possibilidades de lucro por meio da especulação com bônus de carbono nos mercados secundários e, por outro, permitem que as empresas sigam com as mesmas atividades contaminantes, afirmando cumprir as regulações sobre as mudanças climáticas (RIBEIRO, 2011, p. 10).

Outra face deste processo de avanço da ofensiva do capital sobre os recursos naturais vem se desenvolvendo visivelmente na América Latina por meio da intensificação da biopirataria, do desmatamento para expansão das fronteiras agrícolas e dos investimentos em grandes projetos de infraestrutura - energia, transporte e comunicações - cujo objetivo é inserir, cada vez mais, o continente no circuito mundial das commodities, na qualidade de fornecedor de produtos primários à custa da devastação de seus recursos naturais. 
O caso brasileiro é revelador desta tendência: com $51 \%$ de sua pauta de exportações representada por commodities (minérios, grãos, carne e petróleo, etc.), segundo o Instituto de Pesquisa Econômica e Aplicada (IPEA)5, o país vem reforçando um modelo de desenvolvimento marcado pelo uso intensivo dos recursos naturais, ao mesmo tempo em que se acirram as contradições sociais, posto que grande parte de sua biodiversidade se localiza em áreas ocupadas por comunidades ou povos tradicionais e/ou trabalhadores da agricultura familiar, para os quais o avanço do agronegócio constitui uma permanente ameaça à sobrevivência.

O peso das corporações se faz sentir. No caso das grandes projetos de infraestrutura, sucedem-se as denúncias de fraudes ou arbitrariedades no licenciamento ambiental, violação de direitos das comunidades impactadas, precárias condições de trabalho, inclusive com desrespeito à legislação trabalhista nos canteiros de obras, aumento da concentração da terra e da violência, dentre outras.

A despeito disso, as empresas seguem utilizando o discurso da sustentabilidade para incremento de seus lucros. O Índice de Sustentabilidade Empresarial (ISE) da Bolsa de Valores de São Paulo (Bovespa), baseado nos quesitos eficiência econômica, equilíbrio ambiental, justiça social e governança corporativa mostra que ser sustentável também pode ser mais lucrativo. Segundo dados da Bolsa de Mercadorias \& Futuros (BM\&F) Bovespa, no período de março 2011 a março de 2012, o indicador (que serve de parâmetro para investidores com preocupações éticas) se valorizou 5,15\% enquanto o lbovespa, o principal índice da Bolsa, apresenta queda de 5,94\% no mesmo período (ECODEBATE, 2012).

Caldas e Quintela (2011, p. 16) ilustram este paradoxo:

Sob a égide do chamado 'desenvolvimento sustentável', esse "esverdeamento" do capitalismo está diretamente relacionado ao aumento exponencial da

\footnotetext{
${ }^{5}$ O IPEA informa ainda que, entre 2007 e 2010, as commodities tiveram um aumento de $10 \%$ na pauta de exportações brasileiras, tendo destaque os minérios, especialmente o minério de ferro (NASSIF, 2011).
} 


\begin{abstract}
apropriação dos recursos naturais, da expropriação de pessoas e comunidades de suas terras e territórios e, finalmente, da exploração dos agricultores e comunidades tradicionais que, mediante contratos públicos ou privados passam então a serem considerados 'prestadores de serviços ambientais'. Em outras palavras, privatização e financeirização da natureza e crescimento maciço de violações de direitos humanos. Isso, obviamente, não aparece nos comerciais felizes da TV nem nos relatórios de sustentabilidade publicados por grandes empresas.
\end{abstract}

Chama a atenção, no discurso dos ideólogos da economia verde, a ausência de crítica ou mesmo de proposições alternativas quanto aos atuais padrões de produção e de consumo, marcado pela obsolescência programada das mercadorias - com vistas a encurtar a velocidade de rotação do capital - com enormes dispêndios de recursos naturais e de energia, além dos impactos já amplamente constatados do aumento da produção de lixo ${ }^{6}$. Ironicamente, é a própria Organização das Nações Unidas (ONU) que atesta a insustentabilidade deste modelo e sua incompatibilidade com as atuais condições de reprodução da vida no planeta (ORGANIZAÇÃO DAS NAÇÕES UNIDAS, 2005).

\title{
b) Investimentos em novas tecnologias, especialmente voltadas à eficiência energética.
}

O consenso que se estabelece neste ponto diz respeito à necessidade de aumentar os investimentos nas chamadas energias renováveis. A "eficiência energética" é a grande aposta para reduzir as emissões de gases do efeito estufa em curto prazo, o que tem produzido um intenso debate em torno das alterações na matriz energética mundial. A energia solar, eólica, maremotriz, a hidrelétrica e as obtidas a partir da biomassa ou do próprio hidrogênio são consideradas fontes renováveis com um custo ambiental baixo. No entanto, a despeito dos crescentes investimentos neste campo, muitos obstáculos ainda se colocam para que os combustíveis fósseis sejam suplantados: aspectos geopolíticos, sociais e econômicos se entrecruzam neste intrincado campo de possibilidades. Os interes-

\footnotetext{
${ }^{6}$ No total, cerca de 60 bilhões de toneladas de recursos naturais são hoje extraídas anualmente - cerca de 50\% a mais do que há apenas 30 anos (THE WORLDWATCH INSTITUTE, 2010).
} 
ses das grandes corporações petrolíferas e as incertezas do capital quanto à rentabilidade das fontes alternativas têm reiterado um modelo energético que tem produzido impactos significativos sobre o conjunto dos ecossistemas globais, dada, especialmente, a sua relação com as chamadas mudanças climáticas.

A questão que se coloca em relação à pesquisa científica e tecnológica - especialmente as nanotecnologias, as biotecnologias, a geoengenharia, dentre outras - é a necessidade de se atentar para o princípio da precaução7, tendo em vista a voracidade com que o capital se apropria dessas a fim de convertê-las em novos campos de acumulação, pouco se importando com as consequências de médio e longo prazos para a humanidade e para o meio ambiente (SILVA, 2010, p. 136).

\section{c) A instituição de uma governança favorável à transição para uma economia verde.}

Entre as condições apresentadas pelo PNUMA (2011) para alcançar a chamada Economia Verde, encontra-se um conjunto de "condições possibilitadoras", cujo fim é criar uma ambiência favorável (política e economicamente), dentre as quais se destacam: "o estabelecimento de normas rígidas de regulamentação; a priorização de investimentos e gastos públicos em áreas que estimulem o esverdeamento de setores econômicos; a limitação de gastos em áreas que esgotem o capital natural; o uso de impostos e instrumentos que se baseiam no mercado para mudar a preferência do consumidor e promover o investimento verde e a inovação; o investimento em capacitação e treinamento; e o fortalecimento da governança internacional" (PNUMA, 2011, p. 35-41). Isto porque "Os contratos públicos sustentáveis podem contribuir para criar e fortalecer os mercados de bens e serviços sustentáveis [...]. Através do uso de práticas sustentáveis de com-

\footnotetext{
7 A Declaração do Rio de Janeiro/92, em seu Princípio 15, determina: De modo a proteger o meio ambiente, o princípio da precaução deve ser amplamente observado pelos Estados de acordo com suas capacidades. Quando houver ameaça de danos sérios ou irreversíveis, a ausência de absoluta certeza científica não deve ser utilizada como razão para postergar medidas eficazes e economicamente viáveis para prevenir a degradação ambiental. Assim, é possível verificar que o princípio mencionado busca a identificação dos riscos e perigos eminentes para que seja evitada a destruição do meio ambiente, utilizando uma política ambiental preventiva (BOHNERT, 2007).
} 
pras públicas, os governos podem criar uma demanda a longo prazo por bens e serviços verdes [...]. Por outro lado, isto pode levar à maior comercialização de produtos e serviços verdes, promovendo o consumo sustentável” (PNUMA, 2011, p. 35-41).

Neste contexto, cabe perguntar: "O que são bens e serviços sustentáveis e verdes?", "Como deverão ser estruturados seus sistemas de produção e de distribuição?", "Outro aspecto decisivo dessa proposição diz respeito aos sujeitos aos quais caberá sua implementação: 'quem produzirá os 'bens e serviços verdes'?”, "Quais são as condições sociais e as relações de trabalho que mediarão este processo?". Estas e outras questões apresentam-se de forma dúbia, imprecisa, ou não aparecem no texto, o que reforça o seu caráter genérico. Ao adjetivar a Economia Verde como "inclusiva", em nome do combate à pobreza e à desigualdade social, seus ideólogos não tecem um único comentário acerca das formas de apropriação e socialização da riqueza socialmente produzida (sequer de sua desconcentração), deixando evidenciar a falácia de sua propositura.

Ausentes estas definições, em meio a um processo global de crise ${ }^{8}$ e de necessidade do grande capital em driblar a lei do valor, encontrando novas estratégias para a exploração das condições de lucratividade, a governança almejada pela economia verde parece indicar a construção de um arcabouço jurídico-legal amplamente flexível, dando legitimidade às empresas capitalistas para que, fundadas na retórica da sustentabilidade ambiental, construam novas possibilidades de exploração mercantil dos recursos naturais. Trata-se, por assim dizer, de uma maior, mais eficaz e ampla, e, por isso mesmo, mais predatória e perdulária, transformação da natureza e do ambiente comum em mercadoria, em valor de troca, com a consequência de arrastar nela grandes contingentes de populações historicamente alijadas do acesso aos bens e recursos sociais.

Além de os povos tradicionais, ou mesmo as massas trabalhadoras, especialmente dos países e regiões menos economicamente

\footnotetext{
${ }^{8}$ A proposta de criação do fundo de US\$ 30 bilhões, já a partir de 2013, para financiar ações de desenvolvimento sustentável nos países mais pobres sofre a oposição dos países industrializados, como os Estados Unidos, o Canadá e membros da União Europeia. O motivo alegado é a crise econômica, que afeta as maiores economias do planeta.
} 
desenvolvidos do planeta, não serem priorizados nesta nova configuração projetada para a produção e distribuição da riqueza, mantendo-se seu lugar secular de espoliação, a proposta oriunda da economia verde supõe a subtração de seus espaços de vida e trabalho, dos bens que retiraram, por gerações, da natureza, e que ora são transformados em "bens e serviços sustentáveis", ou em "fatores de produção".

\section{CONSIDERAÇÕES FINAIS}

Na contemporaneidade, passados mais de trinta anos da eclosão de uma crise estrutural do capital que, segundo Mandel (1985), levou a economia capitalista ao cerne de uma onda longa de estagnação sem precedentes na curta trajetória histórica deste modo de produção, não se desenha ainda um período ascendente e de relativa estabilidade para o sistema como um todo, antes pelo contrário. As estratégias e ofensivas que perseguem a sua reversão tem sido parciais, outras vezes, ilusórias, mas, em seu conjunto, conservadoras e anticivilizatórias, apontando para a regressão dos níveis de qualidade de vida da maioria dos habitantes do planeta, para o empobrecimento geral das populações do globo, em nome da manutenção da sobrevida da economia mercantil capitalista.

Afirmando os fundamentos contraditórios deste modo de produção e reprodução, vivemos em um dos períodos em que, mais abertamente, se põe a nu a capacidade destrutiva do capital, tanto do trabalho quanto da natureza, as duas reais fontes de criação da riqueza socialmente necessária à reprodução da vida social, o que poderia levar a uma crítica social radical e à construção de estratégias anticapitalistas; mas, ao mesmo tempo, e em consonância com o movimento anteriormente apontado, forjou-se um momento sem precedentes de retrocessos que, por via do Neoliberalismo, da reestruturação produtiva e da mundialização financeira, reencaminha os rumos do desenvolvimento capitalista com vistas a uma crescente mercantilização de todas as esferas da vida, aproveitando inclusive dos elementos da crise para forjar novas estratégias de produção de mais valor, de exploração do homem e da natureza.

Este movimento, enquanto resposta do capital a sua aguda crise, na busca pelo restabelecimento da taxa de lucros, vem acompanhado de um processo que incorpora novas modalidades nas rela- 
ções entre homem e natureza. Se o Capitalismo é incapaz, por sua natureza, de estabelecer relações equilibradas ${ }^{9}$, dada a condição anárquica ${ }^{10}$ de seu processo produtivo, é nos momentos de crise que seu caráter perdulário e predatório tende a se exacerbar. É o que se constata no tempo presente.

Conforme apontam Messias, Oliveira e Araújo (2012, p. 6)

Por muito tempo a natureza foi concebida como um bem coletivo infinitamente disponível para a satisfação das necessidades humanas. Com o agravamento dos problemas ambientais, causados por seu uso e apropriação indiscriminada e descontrolada, em escala global, a sociedade foi se conscientizando da finitude da capacidade de suporte do planeta, além de se atentar para a utilização indiscriminada dos recursos renováveis e não-renováveis, em face dos níveis de degradação atuais.

É nesta direção que Bihr (2010) aponta a “crise ecológica” planetária como uma crise capitalista. Frente a estas, o capital homogeniza, de certo modo, suas estratégias de enfrentamento. Da mesma forma que desregulamenta as relações de trabalho, potencializando as possibilidades da exploração da força de trabaIho e da produção de mais valia, busca a desregulamentação dos mercados, liberdade para agir, saquear e vampirizar mais intensamente os recursos do planeta, procurando encontrar, com base na exploração do meio ambiente, novos nichos de valorização.

A Economia Verde é, precisamente, isso: uma estratégia que busca reorientar a composição orgânica do capital, restabelecendo para os oligopólios e para os grandes aglomerados financeiros internacionais possibilidades de apropriação da natureza em larga escala, e com maior eficiência e eficácia. Busca transformar o que ainda

9 “[...] por sua natureza, o crescimento do modo de produção capitalista conduz sempre a um desequilíbrio" (MANDEL, 1985, p. 51).

10 Sabe-se que a produção confiada a proprietários privados concorrentes, a produção capitalista - tipo generalizado e superior da produção mercantil — não obedece a um plano centralizado, mas se realiza sob o impulso de decisões fragmentárias isoladas. Entre as paredes da empresa capitalista, a produção costuma ser conscientemente regulada e obedece a um plano estabelecido pela administração. Já no processo social global das relações entre as empresas, inexiste a regulação consciente, o planejamento imperativo. O processo social global da produção capitalista caracteriza-se, por isso, pela anarquia (GORENDER, 1996, p. 31). 
permanece "bem de uso comum" em mercadoria, fonte de valor de troca. Procura metamorfosear bens naturais em "ativos ambientais", como as águas, o ar (taxando a emissão de gases), as florestas, passíveis, a partir de então, de serem incorporados nos cálculos estatísticos das finanças capitalistas.

Esta abordagem tenciona ainda mais um dos princípios que os movimentos ambientalistas (de forma geral e não absoluta) e os próprios Estados Nacionais sistematizaram, divulgaram e incentivaram pelo menos nas duas últimas décadas, que é o da sustentabilidade ${ }^{11}$. Analisando criticamente as bases propostas pela Economia Verde, torna-se clara a expectativa de alcançar níveis crescentes de apropriação dos recursos naturais pelas empresas "verdes", de uma forma entendida como ambientalmente segura e justa, ao mesmo tempo em que amplamente lucrativa.

Desta forma, não aparece nenhuma crítica à lógica do sistema, e esta não era mesmo de se esperar, já que se trata de uma estratégia ideopolítica do próprio capital, engolfada desavisadamente por movimentos ambientalistas que continuam a advogar uma suposta neutralidade, e, mesmo agora, ainda não conseguem avançar na avaliação da unidade indissociável entre "questão ambiental" e Capitalismo.

Sendo o que de mais supostamente avançado se apresenta, neste longo meio século de luta ambientalista e de tentativas institucionais e estatais de encontrar respostas à "questão ambiental”, o capital revela, sem sombra de dúvida, sua incompatibilidade com a preservação da natureza: nesta ordem social, o princípio da sustentabilidade social e ambiental não ganhará efetividade. Mais uma vez, revela-se a sustentabilidade propalada pela Economia Verde como um discurso abstrato, de forte teor ideológico, criado pelo Ecocapitalismo como justificação para mais uma fase de apropriação e controle predatório da natureza pela lógica capitalista.

\footnotetext{
${ }^{11}$ O Desenvolvimento Sustentável como expressão da tentativa de estabelecer mecanismos de controle da relação sociedade-natureza regida pelo capital, teve na ECO-92 um dos seus momentos de maior formulação. Vinte anos depois, está claro que o anúncio de uma consciência global planetária não produziu os efeitos esperados e o agravamento da questão ambiental revela que o Desenvolvimento Sustentável esvazia-se, restringindo-se aos discursos.
} 
Frente o desenvolvimento desigual e combinado da economia capitalista em âmbito global, aos países do Hemisfério Sul, segundo sua inserção na divisão internacional do trabalho, cabe a parte mais "suja", e talvez a mais lucrativa destas estratégias, ainda que estes lucros sejam repatriados em nome do capital internacional. Depósitos de lixo dos países de Capitalismo central são fontes e espaços da continuidade e da proliferação da economia "marrom" revestida de aura "verde". No Brasil, pode-se pensar na lentidão ou quase paralisia quanto à incorporação de novas fontes energéticas ao processo de produção, pari passu aos largos investimentos nas fontes poluidoras (retomada das usinas nucleares, pré-sal, barragens inundando florestas, etc.). Mas a Economia Verde oferece a possibilidade da obtenção, pelas empresas poluidoras, dos créditos de carbono negociados nos mercados de ações.

Para o problema das fronteiras agrícolas, os ideólogos do capital respondem com a revisão do Código Florestal brasileiro, flexibilizando responsabilidades frente à devastação dos mananciais e não deixando de fora sequer as parcas Áreas de Proteção Ambiental (APP's) ainda restantes no país.

A necessidade de fragilizar, por um lado, as legislações ambientais existentes, e, por outro, de estruturar novo aporte jurídico e institucional em prol da incorporação da Economia Verde como estratégia de desenvolvimento, figura como resultante da intensificação das disputas intercapitalistas, tendo à direita seus grupos mais ortodoxos que pleiteiam desde o livre jogo do mercado, a desregulamentação financeira, a recessão, o aumento dos juros e impostos, congelamento de salários, corte de gastos sociais e de investimentos etc., até a redefinição dos marcos legais da gestão pública do meio ambiente, acusando-a de obsoleta, velha e burocrática. Constata-se, nestes termos, uma repetição que, se bem observada, parece até irônica ao remontar aos mesmos argumentos usados para quebrar as legislações trabalhistas pelo mundo afora, posto que a Economia Verde supõe a velha e liberal ideia da capacidade de autorregulação dos mercados, desde que dotados de mais liberdade. Ao Estado caberia, por meio de recursos financeiros, impulsionar, incentivar e favorecer as ações ditas sustentáveis, e, de igual maneira, desestimular as práticas consideradas sujas. 
De fato, sob o argumento do esverdeamento da economia, o capital, em face da impossibilidade de escamotear os gravosos efeitos da "questão ambiental", promove o desfecho de um novo escopo ideopolítico, o qual tem como suposto a necessidade de convencer a todos e a cada um da contínua capacidade do sistema de "reformar-se", em prol de seu aprimoramento, beneficiando, assim, o conjunto da sociedade. Enquanto isso, segue a sua trajetória inexorável em busca do aumento de sua lucratividade, apropriando-se vorazmente do conjunto dos recursos planetários - de modo a comprometer as condições de reprodução das múltiplas formas de vida - ainda que o faça sob o nebuloso discurso verde ou em nome da sustentabilidade.

Assim, a Economia Verde revela todo o seu cariz de ideologia. Lembrando Mandel (1985, p. 16-17):

Toda ideologia não é apenas uma fraude, mas um reflexo específico e socialmente determinado da realidade que mistifica [...] A crença na onipotência da tecnologia é a forma específica de ideologia burguesa no capitalismo tardio [...]. A ideologia do racionalismo tecnológico pode ser apresentada como uma mistificação que esconde a realidade social e suas contradições [...] (MANDEL, 1985, p. 16-17).

Por fim, desvelar a natureza das ofensivas ideológicas do Capitalismo constitui tarefa de primeira ordem, especialmente em tempos de crise estrutural. Entrar na disputa pela reorientação dos movimentos ambientalistas, no caminho do ecossocialismo, de natureza essencialmente anticapitalista, assim como pela incorporação da pauta ambiental nas demais lutas sociais, faz-se condição fundamental para defender a continuidade de nossa posse e permanência no planeta, tendo como suposto uma sociedade humanamente emancipada. Se a insustentabilidade planetária resulta de uma ordem social perdulária e destrutiva (não natural), somente com a superação desta ordem social é possível construir uma sociedade verdadeiramente sustentável.

\section{REFERÊNCIAS}

ANTUNES, A. Economia Verde: as contradições do discurso ambiental no cerne do sistema capitalista. 10 nov. 2011. Disponível em: <http://www.ecodebate.com.br/2011/11/10/economia-verde- 
-as-contradicoes-do-discurso-ambiental-no-cerne-do-sistema-capitalista-por-andre-antunes/>.

BIHR, A. Da grande noite à alternativa: o movimento operário europeu em crise. São Paulo: Boitempo, 2010.

BOHNERT, Luciana Neves. Princípio da precaução no Direito Ambiental. 5 nov. 2007. Disponível em: <http://www.webartigos. com/artigos/principio-da-precaucao-no-direito-ambiental/2558/>. Acesso em: 8 maio 2008.

CALDAS, A; QUINTELA, S. Esverdeando o capitalismo: a farsa das corporações para a Rio + 20. In: Sustentabilidade e Desenvolvimento. Le Monde Diplomatique Brasil, São Paulo, ano 5, n. 53, dez. 2011. Suplemento Especial.

ECODEBATE. Cidadania e Meio Ambiente: “Empresas 'sustentáveis' são mais lucrativas: dados sobre companhias 'verdes' serão divulgados na Rio+20" < Disponível em 04/05/2012>

GORENDER, J. Prefácio. In: MARX, K. O Capital. São Paulo: Nova Cultural, 1996. (Coleção Os Economistas). v. 1.

Löwy, M. Michael Löwy critica Rio+20 e a propaganda da 'economia verde'. Caros Amigos, São Paulo, 23 mar. 2012. Entrevistadora Bárbara Mengardo. Disponível em: <http://carosamigos. terra.com.br/index/index.php/cotidiano/1046-michael-loewy-critica-rio20-e-a-propaganda-da-economia-verde>.

MANDEL, E. O capitalismo tardio. São Paulo: Abril Cultural, 1982. (Coleção Os Economistas).

MESSIAS, J. R; OLIVEIRA, A. R. S; ARAÚJO, N. M. S. As expressões da "questão ambiental" sob a ótica dos dirigentes sindicais de Aracaju. In: ENCONTRO ANUAL DA ANDHEP, 7., 2012, Curitiba (PR). Anais... Curitiba (PR): ANDHEP, 2012. p. 6-12.

NASSIF, Maria Inês. O avanço das commodities. Desafios do Desenvolvimento, Brasília, ano 8, n. 66, p.40-46. Disponível em: <http://desafios.ipea.gov.br/images/stories/PDFs/desafioso66 completa.pdf>.

ORGANIZAÇÃO DAS NAÇÕES UNIDAS. Vivendo além dos nossos meios. 2005. Disponível em: <http://www.biodiversidade.rs.gov. 
br/arquivos/1161804167A_Avaliacao_Ecossistemica_do_Milenio. pdf>. Acesso em: 24 jan. 2007.

PNUMA. Rumo a Economia Verde: caminhos para o desenvolvimento sustentável e a erradicação da pobreza: síntese para tomadores de decisão. 2011. Disponível em: <http://www.pnuma. org.br/admin/publicacoes/texto/1101-GREENECONOMY-synthesis_PT_online.pdf>.

RIBEIRO, S. As novas fronteiras de mercantilização da natureza. In: Sustentabilidade e Desenvolvimento. Le Monde Diplomatique Brasil, São Paulo, ano 5, n. 53, dez. 2011. (Suplemento Especial).

SILVA, Maria das Graças e. Questão ambiental e desenvolvimento sustentável. Um desafio ético ao Serviço Social. São Paulo: Cortez, 2010.

THE WORLDWATCH INSTITUTE. 2010 Estado do mundo transformando culturas: do consumismo à sustentabilidade. 2010. Disponível em: <http://www.worldwatch.org.br/estado_2010.pdf>. 